\title{
Patient profile, indications, complications and Evaluation of Septoplasty outcome in a Base Hospital in Sri Lanka
}

\author{
Rubasinghe M.S. , De Silva M.D.K., Wanasinghe W.M.S.C.L.,
}

De Livera R.J.K., Wimalaratna T.P.S.K.

ENT Department Base Hospital Avissawella, Sri Lanka.

\begin{abstract}
Introduction

A large percentage of the population has some degree of deviated nasal septum causing symptoms of nasal obstruction. Nasal septoplasty is the surgery of choice for symptomatic nasal septal deviations.
\end{abstract}

\section{Objective}

To describe the patient profile, indications, complications and evaluation of septoplasty outcome using Nasal Obstruction Symptom Evaluation scale. (NOSE)

Method: Interviewer administered questionnaire and data collection sheet were the study instruments used for prospective (30 subjects) and retrospective (35 subjects) components respectively.

\section{Results}

Two thirds of the patients were in the 16-30 age group, $42 \%$ females and $48 \%$ males. $35 \%$ had a history of nasal trauma. 53\% presented with allergic rhinitis and $20 \%$ with turbinate hypertrophy. More than $2 / 3^{\text {rd }}$ presented with deviations in the Cephalic septum and S Shaped septum. $84 \%$ had dislocation from the maxillary crest.

More than $90 \%$ of the subjects underwent, quadrangular cartilage trimming, vomer removal, perpendicular plate of ethmoid removal and maxillary Crest gouge. Plastic splints were used in $73 \%$ of the subjects and antibiotic was used in $26 \%$. No septal perforations, infections or bleeding was reported from any of the 65 subjects.
Pre and Post-operative (at 3 months), NOSE score was Mean 9.46; SD 4.36 and Mean 0.53; SD 0.97 respectively. When t-Test: Paired Two Sample for Means was calculated t stat was 11.7153, while t critical two tail value was 2.0452 indicating that there is a statistically significant difference between the two means $(\mathrm{p}=0.05)$.

\section{Conclusion}

Septoplasty gave good results with minimum complications, resulting in significant improvement in disease specific quality of life.

\section{Introduction.}

The Nose is a midline facial structure meant not only for the purpose of breathing and smell but also associated with the facial aesthetics more than nay structure in the face. It is composed of a skeleton covered by "skin soft tissue envelope". The nasal skeleton is composed of several bones and cartilages of different shape connected together. The nasal septum is a central support structure for the nose. A straight septum is the exception rather than the rule.

Difficulty in breathing due to Nasal obstruction and related complaints is the most common complaint in rhinology practice. About $80 \%$ of the general population has some degree of deviated nasal septum. Nasal septoplasty is the surgery of choice for symptomatic nasal septal deviations ${ }^{1}$

Septal cartilage provides structural support to the nasal dorsum while maintaining a remarkable degree of elasticity. It may be deviated as a part of a damaging process during in-utero development or during birth. Acquired septal deviations may occur as a result of a traumatic impact in childhood or adult life. Childhood trauma brings 
more damage to the growing septum as any degree of damage gets worse with time.

These patients may present with a history of sinusitis, allergic rhinitis, obstructive sleep apnoea, atypical facial pain, previous nasal surgery or recent nasal trauma. They often relate symptoms of unilateral or bilateral nasal airway obstructions that is unrelieved with nasal decongestants or steroid nasal sprays ${ }^{2}$.

If there is a visible nasal septal deviation with no other identifiable causes e.g. polyps, turbinate hypertrophy, allergies. etc. it is indicated for them to have a nasal septoplasty. There are other indications for septoplasty such as to gain access to posterior nasal passage for procedures like to control a posterior bleeding by cautery or to pack the nasal cavity for control of epistaxis. Moreover, as a part of Endoscopic Sinus surgery this surgery is done to correct deviations that blocks the osteomeatal complex. Also it can be done as a part of a complex procedure like a cosmetic rhinoplasty and to access a pituitary tumour via the nose ${ }^{3}$

There have been studies done in other countries on septoplasty ${ }^{4}$ and on quality of life assessment in patients with nasal obstruction before and after septoplasty ${ }^{5}$. However, there are no published literature on nasal septoplasty or on patient satisfaction following septoplasty in Sri Lanka. This study attempts to fill that void.

The aim of this study was to describe the patient profile, indications, complications and evaluation of Septoplasty Outcome using NOSE (Nasal Obstruction Symptom Evaluation) scale. The NOSE scale is a validated outcome instrument assessing quality of life related to nasal obstruction ${ }^{6}$ (Table1).

The results of this study were analysed on SPSS software. "Paired t test" was also used.

\section{Material and Methods.}

\section{Study setting}

Study was carried at Avissawella Base Hospital in the Western Province of Sri Lanka.in 20142016.

\section{Study Design}

The Research consisted of Retrospective and Prospective components and was conducted on patients who presented with signs and symptoms attributed to septal deviation, and managed and followed up in the ENT unit by the author.

\section{Study Instruments}

For the Prospective study a Pre-Tested Interviewer administered Questionnaire and for the Retrospective study, a data collection sheet containing the same questions as in the Prospective study, without the NOSE Scale Evaluation section, were used.

In the retrospective study, all patients operated by the author during 2013-2015 period was considered. Data was collected by referring to patient data sheets kept in the hospitals record room and patient's clinic records using the above data collection sheet.

The prospective study was carried out, using the above-mentioned questionnaire inclusive of validated Nasal Obstruction Symptom Evaluation (NOSE) scale by Stewart et al ${ }^{6}$. The study population was all patients who underwent septoplasty due to nasal obstruction during a one-year period, operated on by the author. In the Prospective study, as in previous published studies the NOSE questionnaire was used preoperatively and at $3^{\text {rd }}$ month post operatively ${ }^{6}$. The difference in the mean score between preand post-operative assessments was calculated (Table 1).

Informed consent was taken from all patients explaining the procedure, benefits, possible complications and importance of regular follow up post operatively.

\section{Inclusion criteria}

Patients with age more than 18 and less than 50 years of both sexes with septal deviation were included in the study. 
ISSN : $2012-855 x$

Ceylon Journal of Otolaryngology

(C) 2016; College of Otorhinolaryngologists and Head and Neck Surgeons of Sri Lanka

\section{Exclusion Criteria}

Patients with major systemic diseases.

\section{Ethical Clearance}

Ethics Review Committee, Faculty of Medicine, University of Kelaniya, Sri Lanka (Ref$\mathrm{P} / 23 / 03 / 2014)$.

\section{Results.}

Study was conducted on 65 patients (35 retrospective and 30 prospective).

Both components of the study taken together there were $42 \%$ females and $48 \%$ males, who presented with signs and symptoms attributed to septal deviation, and managed and followed up. Seventy-three percent belonged to the age group of $16-30$ years while $20 \%$ and $7 \%$ were from 31 40 age group and 41-60 age group respectively (Figure 1).

More than one third (nearly 35\%) of the patients had a history of nasal trauma. Out of those who had a history of nasal trauma, female to male ratio was 1:2.5. However out of 65 subjects only 2 patients had undergone any previous nasal surgery.

Considering the associated conditions of allergic rhinitis, turbinate hypertrophy and nasal polys; majority (53\%) presented with allergic rhinitis, followed by turbinate hypertrophy in $20 \%$ of the patients. Only a small percentage (7\%) of patients presented with nasal polyps.

When the anatomical location of the deviation was considered more than two thirds presented with deviations in the Cephalic septum (64\%), S Shaped septum (67\%) and dislocation from the maxillary crest (84\%). Furthermore, nearly a half (49\%) presented with deviations in the Caudal septum while $4 \%$ had deviations in the duplicated caudal end (Table 2). Moreover, Mucoperichondrial tears were seen in 31\% of the cases.

When the Surgical Procedure to correct, the deformity was analysed vast majority underwent, quadrangular cartilage trimming (98\%), Vomer removal (95\%), perpendicular plate of ethmoid removal (95\%) and maxillary Crest gouge (93\%) (Table 3)

Plastic splints were used in $73 \%$ of the cases, out of which $64 \%$ were one sided splints. Haemostasis was obtained with Vaseline packs with Tretracort in $73 \%$ of the cases while Merocel packs were used in $27 \%$. In $75 \%$ of the cases, packs were kept only for 1 day while in $24 \%$ packs were kept for 2 days. It was noteworthy that antibiotic was used only in $26 \%$ of the patients in this series.

After 1 week post operatively 4\% presented with syneachea formation while no Septal perforations, infections or bleeding was reported from any of the 65 cases in this series.

In the Prospective study component in addition to the evaluation of the above criteria; symptoms before septoplasty and one month after septoplasty was evaluated using the NOSE Scale (Table 1) and patient based outcome on the subjective opinion was analysed using paired $t$ test.

In this series of patients ( $n=30)$, the preoperative Nasal Obstruction Symptom Evaluation (NOSE) scores of all the patients were compared to the Post-operative NOSE scores to know the functional outcome of the surgical procedure. On statistical analysis of NOSE score of patients at baseline and at post-operative 3 month follow up, Mean value of 9.46 with a SD of 4.36 and Mean value of 0.53 with a SD of 0.97 was obtained respectively. When t-Test: Paired Two Sample for Means was calculated t stat was 11.7153 , while t critical two tail value was 2.0452 indicating that there is a statistically significant difference between the two means $(\mathrm{p}=0.05)$.

\section{Discussion.}

Patients who presented and underwent Septoplasty were relative young. Nearly 75\% were in the age group of 16-30 years with slightly more male patients. In this study, it was observed that post-operative complications of Septoplasty Surgery were minimum. Antibiotics use was limited to one fourth of the patients and the packs 
Rubasinghe M.S., De SilvaM.D.K., WanasingheW.M.S.C.L., De LiveraR.J.K., WimalaratnaT.P.S.K. Patient profile, indications, complications and Evaluation of Septoplasty outcome in a Base Hospital in Sri Lanka

Volume : 5; Issue1; pp $14-18$

were removed after 1 day in three thirds of the patients.

As shown by the NOSE scale evaluation very significant improvement in obstructive symptoms was observed 3 months after the surgical intervention. This observation was quite consistent with the observations reported by Michael G Stewart et al $2004{ }^{6}$, Baumann I, 2007 ${ }^{7}$ and Mira A Beg, M Ahmed $2014{ }^{8}$.

In this series of patients, who were predominantly young adults, septoplasty gave good results with minimum complications. NOSE Scale; a validated instrument showed that Septoplasty surgery carried out in a Base Hospital in Sri Lanka, resulted in significant improvement in disease specific quality of life with patient satisfaction.

\section{Key Messages.}

Septoplasty gave good results with minimum complications, resulting in significant improvement in disease specific quality of life.

Tables Figures and Illustrations.

Table 1: Nasal Obstruction Symptom Evaluation (NOSE) Scale

\begin{tabular}{|l|c|c|c|c|c|}
\hline & $\begin{array}{c}\text { Not a } \\
\text { prob- } \\
\text { lem }\end{array}$ & $\begin{array}{c}\text { Very } \\
\text { mild } \\
\text { prob- } \\
\text { lem }\end{array}$ & $\begin{array}{c}\text { Mod- } \\
\text { erate } \\
\text { prob- } \\
\text { lem }\end{array}$ & $\begin{array}{c}\text { Fairly } \\
\text { bad } \\
\text { prob- } \\
\text { lem }\end{array}$ & $\begin{array}{c}\text { Se- } \\
\text { vere } \\
\text { prob- } \\
\text { lem }\end{array}$ \\
\hline $\begin{array}{l}\text { Nasal Con- } \\
\text { gestion/Stuff- } \\
\text { iness }\end{array}$ & 0 & 1 & 2 & 3 & 4 \\
\hline $\begin{array}{l}\text { Nasal block- } \\
\text { age/obstruc- } \\
\text { tion }\end{array}$ & 0 & 1 & 2 & 3 & 4 \\
\hline $\begin{array}{l}\text { Trouble } \\
\text { breathing } \\
\text { through nose }\end{array}$ & 0 & 1 & 2 & 3 & 4 \\
\hline $\begin{array}{l}\text { Trouble } \\
\text { sleeping }\end{array}$ & 0 & 1 & 2 & 3 & 4 \\
\hline $\begin{array}{l}\text { Unable to } \\
\text { get enough } \\
\text { air through } \\
\text { during exer- } \\
\text { tion }\end{array}$ & 0 & 1 & 2 & 3 & 4 \\
\hline
\end{tabular}

\section{0,1,2,3, and 4 Scores allocated}

Table 2: Anatomical location of the deviation

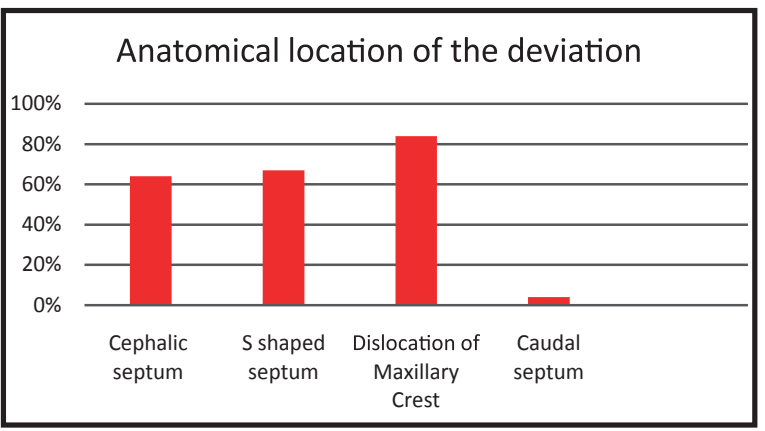

Table 3: Surgical procedure to correct the deformity

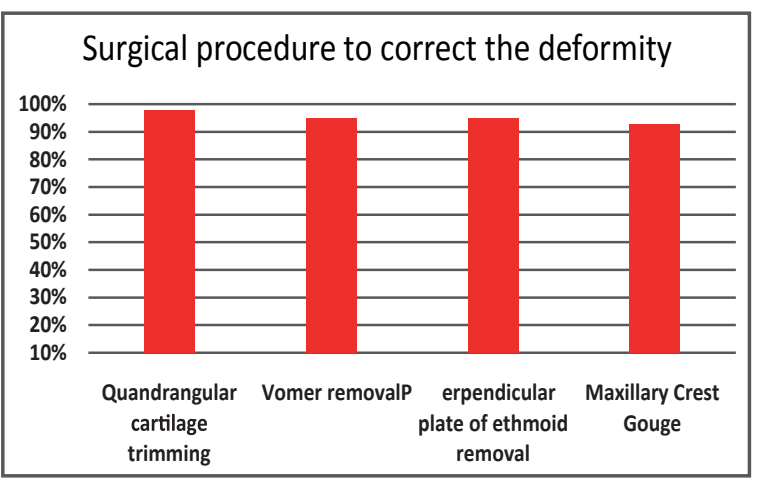

Figure 1: Age Structure of the Patients

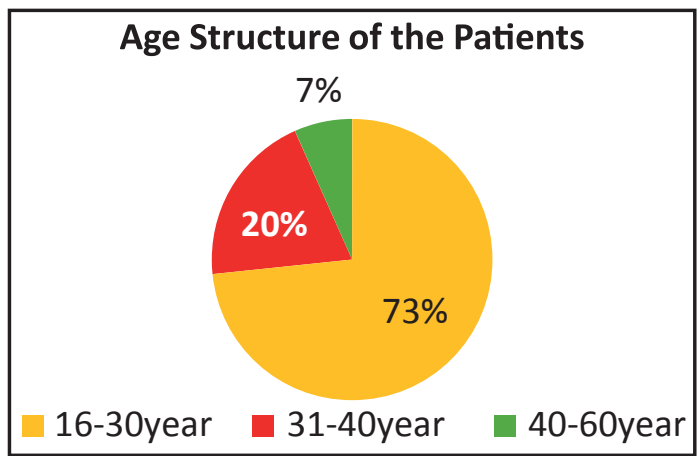




\section{References.}

1. Jessen, M., Malm, L., The Importance of $\mathrm{Na}$ sal airway resistance and Nasal symptoms in the selection of patients for septoplasty. Rhinology 1984 Sep; 22:157-64

2. Alexander, D., Karatzanis et al, Septoplasty outcome in patients with and without allergic Rhinitis, Rhinology 2009 Dec; 47: 444-49

3.Siegel, N.S., Gliklich, R.E., Taghizadeh, F., Chang, Y., Outcome of septoplasty. Otolaryngol Head and Neck Surgery 2000 Feb; 122(2):228-32

4. Calder, N.J., Swan, I.R., Outcomes of septal surgery. J laryngol Otol 2007 Nov;121(11): 1060- 1063

5. Stewart, M.G. et al., Development and validation of the Nasal Obstruction Symptom Evaluation (NOSE) scale., Otolaryngol Head Neck Surg 2004 Feb;130(2):157-63
6. Stewart, M.G. et al., Outcome after nasal septoplasty, results from the Nasal obstruction Septoplasty Effectiveness (NOSE) study. Otolaryngol Head and Neck Surg 2004 Mar; 130(3): $283-90$

7. Baumann, I., Quality of life before and after septoplasty and rhinoplasty. (internet). GMS Current Topics Otorhinolaryngol Head Neck Surg 2010 Nov; 9:, Doc06. Available at http://www.egms.de/static/en/journals/ cto/2011-9/cto000070.shtml.

8. Mira, A.B., Ahmaed, M., Evaluation of Septoplasty Outcome Using Nose (Nasal Obstruction Symptom Evaluation) Scale., International Journal of Scientific Research. 2014 Feb; 3(2):359-60 